\title{
Time estimation and concurrent nontemporal processing: Specific interference from short-term-memory demands
}

\author{
C. FORTIN, R. ROUSSEAU, P. BOURQUE, and E. KIROUAC \\ Université Laval, Quebec, Canada
}

\begin{abstract}
Previous studies have shown that the effect of concurrent nontemporal processing on time estimation may vary depending on the level of difficulty of the nontemporal task. This is commonly interpreted within the context of so-called distraction/interruption models of temporal processing, which propose that as concurrent task difficulty or complexity is increased, temporal processing receives less attention. We hypothesize that the effect of nontemporal processing does not depend on the level of difficulty as such, but rather on the extent to which the concurrent nontemporal task specifically involves processing in short-term memory. Four experiments were run in which the short-term memory requirements of concurrent tasks were systematically varied, although all of the tasks were of comparable levels of difficulty. In the first experiment, the effect of memory search on simultaneous temporal productions was proportional to the number of items to search. As with reaction time, produced intervals were shown to increase linearly with the number of items in the memorized set. In Experiment 2, a visual search involving some load on short-term memory interfered in the same way with time production, although to a lesser extent. The last two experiments showed that performing attention-demanding visual search tasks that did not involve short-term memory did not lengthen simultaneously produced time intervals. This suggests that interference of nontemporal processing on time processing may not be a matter of nonspecific general purpose attentional resources, but rather of concurrent shortterm-memory processing demands.
\end{abstract}

Prospective timing occurs when one is required to estimate the duration of a temporal interval that is to be presented. In such a situation, it is often reported that estimated duration decreases as a result of increasing concurrent nontemporal processing demands. This is commonly interpreted within the context of so-called distraction/interruption models of temporal processing, which propose that as concurrent task difficulty or complexity is increased, temporal processing receives less attention (Block, 1990; Brown, 1985; Fortin \& Rousseau, 1987; Fraisse, 1984; Hicks, Miller, \& Kinsbourne, 1976; McClain, 1983; Rousseau, Fortin, \& Kirouac, in press; Thomas \& Cantor, 1978; Vroon, 1970). The reduction of attention to temporal processing is assumed to result in less temporal information and, consequently, to shorter perceived duration. In spite of the accumulation of evidence, the distraction models still remain quite informal, which led Block to state that "Terms like attention to time and temporal information processing are unacceptedly vague"' (p. 22).

We believe that two basic questions should be addressed for some progress to be achieved. First, temporal-

This research was supported by Grants OGP0046422 and A0692 from the Natural Science and Engineering Research Council of Canada to the first and the second authors. Correspondence should be sent to C. Fortin, École de Psychologie, Université Laval, Québec, Canada G1K 7P4 (e-mail: fortincl@vml.ulaval.ca). processing models must refer more formally to the sharing of attention between temporal and nontemporal processing. Second, interpretation of dual-task interaction involving temporal and nontemporal processing must take into account the current theoretical context and methodological knowledge on time-sharing between processes.

Recently, a number of authors have proposed psychophysical timing models incorporating some form of attentional control (Meck, 1984; Rousseau, Picard, \& Pitre, 1984). These belong to a class of models in which temporal processing is defined as the accumulation of temporally coherent information (events or pulses) from an internal source (Church, 1984; Hicks et al., 1976; Killeen \& Weiss, 1987; Kristofferson, 1977). The accumulation process is under the control of a gate that enables the accumulation while in an "on" state. The internal representation of the duration of a given interval is some transformation of the number of pulses or events accumulated from the onset to the offset of that interval. The gate is seen as being under attentional control (Meck, 1984; Rousseau et al., 1984). Concurrent nontemporal processing would put the gate in an "off" state, and would temporarily interrupt the accumulation process. Accumulation would resume after the completion of nontemporal processing.

When a time interval is under the control of an experimenter, accumulation interruption will reduce temporal information, thus resulting in an underestimation of the actual duration of a given interval. When a time interval 
of a given duration is to be produced by a subject, a criterion count corresponding to that interval is set in longterm memory (Church, 1984). Accumulation proceeds from onset of the time interval until the accumulated count reaches the criterion, at which point the production is terminated. In such a case, interruption in the accumulation process will result in a lengthening of the produced interval that is proportional to the duration of the interruption, because more real time is required to accumulate the criterion number of counts (Rousseau et al., 1984). This type of scheduling, in which a process $\mathrm{A}$ is interrupted to complete process $B$ and afterwards resumes, has been described by Schweickert and Boggs (1984) as preemptive time-sharing of common resources. However, these temporal-processing models do not address the issue concerning the nature of the shared attentional resources. For these resources to be identified, a close examination of the nontemporal tasks interfering with temporal processing is required.

Dual-task methodology commonly assumes that a decrement in performance in one or both tasks performed concurrently results from the sharing of common processing resources (Gopher \& Donchin, 1986). Originally, cognitive processes were assumed to require resources from an undifferentiated fixed-capacity resource pool (Kahneman, 1973, Norman \& Bobrow, 1975). Consequently, given any two tasks to be performed concurrently, if processing demands were increased in one of the tasks, both or the lowest priority task would show a performance decrement.

Within the context of studies investigating the effect of nontemporal tasks on time judgments, the approach has been to use complex nontemporal tasks (e.g., Brown, 1985; Hicks et al., 1976; McClain, 1983; Thomas \& Cantor, 1978; Vroon, 1970). As noted by Brown and West (1990), very different tasks have been used: card sorting, manual tracking, shadowing for word recognition, tone discrimination, or letter identification. These studies implicitly or explicitly assumed nonspecific resources, so interpretation of observed effects has commonly been related to a general effect of nontemporal task complexity or difficulty. Increasing nontemporal-processing complexity or difficulty induced increased distortion in time judgments, suggesting that time estimation needed a general attentional resource allocation.

Interpretation of dual-task interaction is complicated by the fact that current theorizing considers resources to be distributed among multiple specific pools (Navon \& Gopher, 1979; Wickens, 1980, 1984). Wickens proposed a number of pools following an information-processing analysis of cognitive processing. These pools can be roughly summarized as encoding, central processing, and response processing under visuospatial or auditory-verbal coding. The distribution of processing resources presents basic difficulties for the interpretation of disruption of temporal processing by nontemporal processing.

Most nontemporal tasks that have been used in research on time estimation are complex, and all the processing components (perceptual, central, or motor) are likely to be involved during the concurrent execution. Therefore, it becomes quite difficult to specify the source of the observed effects on time estimation. Brown and West (1990) devised a dual-task situation in which the duration of a number of visual stimuli had to be processed concurrently. All of the stimuli required temporal processing, so it could be safely assumed that they shared common resources. The results led Brown and West to conclude that timing was an effortful process that draws from limited nonspecific attentional resources. Although the approach is interesting, it leaves open the question of identification of the specific resources required for temporal processing.

In an attempt to clarify the double issue of temporalprocessing interruption and specificity of interference from nontemporal processing, Fortin and Rousseau (1987) devised a dual task in which temporal-interval production and memory search were executed concurrently. Their subjects were trained to produce a sequence of two keytaps at roughly 2 -sec intervals. In an experimental trial, they first had to memorize a digit set. They then initiated the time production, during which, $0.5 \mathrm{sec}$ after onset, a digit probe was presented for recognition. The production was terminated by the recognition response. Produced intervals were shown to increase linearly with the number of digits in the memorized set. Fortin and Rousseau, following Rousseau et al. (1984) argued that preemptive time-sharing occurred, and that timing was interrupted to perform the memory search and it resumed afterward. The duration of the interruption was proportional to the number of items to search in memory. They showed the slope of temporal production versus memory-set size to be about $22 \mathrm{msec}$, suggesting that comparing the test item with one member of the memory set interrupted the accumulation process for approximately $22 \mathrm{msec}$.

This combination of time production and memory search appeared to be especially suitable to tackle the problem of the dual-task interference specificity. First, perceptual processing requirements during the time production were constant and minimal, because whatever the memory-set size, a single stimulus was presented during the interval. Furthermore, there was no motor response component in the nontemporal task during the time production itself, because responses in both tasks were integrated; when the subject pressed one of two buttons to end the interval, he/she simultaneously gave the response to the search task. Thus, concurrent processing was limited to the comparison process, which is known to operate in short-term memory. The observed interference led Fortin and Rousseau (1987) to conclude that time processing involves short-term memory. This is supported by authors such as Zakay (1990), who states that shortterm memory should be involved in estimation of short intervals, and Gibbon, Church, and Meck (1984), who included short-term memory as one of four major parts of a psychological process model of timing.

The purpose of the present study is to show interference from nontemporal processing on temporal processing to 
be specific on sharing short-term-memory resources. The methodology proposed by Fortin and Rousseau (1987) is of particular interest, because it uses a search task to manipulate nontemporal processing. Search tasks are among the most extensively studied tasks in the informationprocessing paradigm. Systematic variations of search conditions on reaction time provide a powerful diagnostic means to identify the specific processing demands in a given situation. In the present series of experiments, search conditions were manipulated in order to systematically vary demands on short-term memory. On one hand, the number of items included in the search were varied, and on the other hand, the demands on short-term memory were reduced over experimental conditions by comparing memory and visual search. Some search tasks involving minimally short-term memory have previously been shown to entail attentional control, as shown by an increase in response latency as a function of number of items to be compared. In fact, many visual search tasks require attentional control, even if there is no need to operate in short-term memory (see Rabbitt, 1984, for a review). More specifically, it should be possible to develop experimental conditions in which increases in response latencies as a function of number of items to be processed would not be parallel to increases in time production, if common resources are not shared.

The first experiment aims at reproducing Fortin and Rousseau's (1987) results while including a control reaction time condition. The present series of experiments systematically compares the effect of different search tasks on time estimation, so a reaction time condition appears as a basic control condition to support an interpretation in terms of processing demands. As was found in Fortin and Rousseau's experiment, temporal productions are expected to increase with the number of items involved in the search. These data should parallel those obtained in the reaction time paradigm.

In Experiments 2, 3, and 4, we attempt to show that it is not the search task per se, nor the attentional control required during the search that interfere with time production. Visual search tasks are performed concurrently with time production. Because these tasks put a minimal load on short-term memory, they should induce little interference with time production. In these experiments, there should be an increasing dissociation between reaction time and time-production data as the short-termmemory load in the search task decreases.

\section{GENERAL METHOD}

\section{Subjects}

All the subjects were young, normal adult volunteers, who were paid $\$ 5$ per session. They were all naive to the experimental hypotheses.

\section{Apparatus}

The experiments were all conducted with the same apparatus, except for Experiment 2; in this case, the apparatus will be described in the Procedure section of Experiment 2. Stimulus and feedback presentations as well as data collection were handled by a PC-ATcompatible computer using MEL (Micro Experimental Laboratory) software system. The experiments took place in a sound-attenuating test chamber. The visual stimuli were presented through an IBM color monitor with a $20 \times 27 \mathrm{~cm}$ screen, including a VGA graphic board. The subject was seated approximately $60 \mathrm{~cm}$ in front of the screen. The temporal productions and the responses to the search tasks were given by pressing one or the other of three keys of a response box; the subjects were instructed to use their preferred hand to respond. Reaction time and temporal-production measures were taken to the nearest millisecond.

The beginning of the experiments, as well as the beginning of each block and trial, were controlled by the subject; when ready, he/she pressed a key located in the middle of the three keys of the response box. Feedback for the temporal-production task was provided visually within a $10 \%$ window centered on the target interval, informing the subject that the produced interval was too long, too short, or correct. Feedback for the search task was also given visually, informing the subject if the response was correct, or if an error had been made. In the time-production practice sessions, feedback was generally given to help the subjects stabilize their productions. However, when the search task was combined with temporal production, feedback was given for search-response accuracy only.

\section{Procedure}

The procedure was generally the same in all four experiments; exceptions will be described in the specific procedure sections. In each experiment, two main conditions were tested-reaction time and search/temporal production. In the reaction time condition, the subjects performed the search tasks with instructions to respond as quickly as possible while minimizing errors. In the search/ temporal-production condition, they first practiced to produce a given time interval in order to stabilize time-production performance. Within a given experiment, the target interval did not vary. After the practice sessions, the subjects performed the search/temporalproduction task in the experimental sessions. In both conditions, sessions were divided into blocks of trials, with a 30 -sec rest between blocks. In the search/temporal-production condition, the first block of the experimental sessions aimed to reset the production around the target duration. In this block, the subjects simply produced the interval with feedback, as in the practice sessions, which helped them to reset the production. The search/temporal-production experimental trials occurred in the last four blocks of the experimental sessions. In these blocks, the subjects were instructed to produce the interval as accurately as possible while minimizing errors in the search task. In the search/ temporal-interval condition, as in the reaction time condition, the number of target-present trials was the same as the number of target-absent trials. In each experiment, the subjects were introduced to the general setting and requirements in a separate introductory session. Before introducing a new condition, they were given about 20 practice trials. In Experiments 1,3 , and 4 , two different groups were run in the reaction time and search/temporal-production conditions to avoid any interference between response patterns. In Experiment 2, which was conducted before the others, the same subjects were run in both conditions. However, they were divided in two groups, which were run in a counterbalanced order in both conditions.

Repeated measures analyses of variance (ANOVAs) were carried out on mean reaction times and mean temporal intervals. Only effects significant at least at $p<.01$ were considered to be statistically significant. Before performing each analysis, data more than three standard deviations from the mean over all observations were discarded. Trials in which an error was made in the search were also eliminated. 


\section{EXPERIMENT 1}

In Experiment 1, a memory-search task was combined with a time-production task. Fortin and Rousseau (1987) have previously shown that interpolating such a task in temporal productions leads to time-interval-production functions that parallel those classically reported in reaction time experiments. However, reaction time data were not collected in Fortin and Rousseau's experiment. It was therefore difficult to explain the fact that the slopes of mean temporal productions as a function of memory-set size were lower than the slopes of the reaction time functions found in previous experiments, although this could result from time-sharing strategies as well as from the specific setting of the experiment. Experiment 1 was conducted to allow a direct comparison of the effect of varying the load on memory search in reaction time and search/time-production paradigms.

\section{Method}

Subjects. Twelve subjects, ranging in age from 20 to 38 , took part in this experiment. Five subjects were run in the reaction time condition, and 7 in the time-production condition.

Stimuli. All the stimuli used in the experiment were chosen from a set of ten digits (0-9). The viewing size of the individual elements was $0.4^{\circ}$ in width and $0.2^{\circ}$ in height. Memory-set size varied from 1 to 6; display size was always 1 .

Procedure. In the reaction time condition, there were three experimental sessions. The subject initiated the trial by pressing the middle key, which successively displayed the memory-set elements. Each element appeared for $1,200 \mathrm{msec}$, in a random order. After the memory-set presentation, a central fixation dot appeared, which remained present until the subject again pressed the middle key. A target appeared $500 \mathrm{msec}$ after this keypress. The subject responded as quickly as possible by pressing the left key if the target was absent from the memory set (negative-response trial), and the right key if the target was present (positive-response trial). Visual feedback immediately followed each response. When ready, the subject initiated the next trial.

In the time-production condition, there were three temporalproduction practice sessions and two experimental sessions. The practice and experimental sessions, in both conditions, were composed of five 48-trial blocks. The target interval was 2 sec.

The practice sessions enabled the subject to stabilize temporal productions. In a trial, the sequence of events was as follows. The subject started the interval by depressing the middle key. An arrow appeared on the screen $500 \mathrm{msec}$ later, informing the subject to end the interval, after the 2-sec subjective interval, by depressing the right or the left key. This was to familiarize the subject with the dual response. In the first four blocks, visual feedback for the temporal-production task was provided. In the fifth block, no feedback was given.

In the experimental sessions, after the first block of temporalproduction practice trials, the subject participated in four blocks in which he/she produced the temporal interval while simultaneously performing a memory-search task. The subject initiated the trial by pressing the middle key, and the memory set was then displayed, as in the reaction time condition. After the memory-set presentation, the subject could begin the temporal interval by again pressing the middle key. A target appeared $500 \mathrm{msec}$ after the keypress, and remained present until the subject ended the interval by pressing the left or the right key, depending on the absence or the presence of the target in the memory set. Visual feedback was then given on search-response accuracy. In fact, the search-task conditions were the same as in the reaction time condition, with the exception that the response was not speeded, but was combined with temporal production.

In the search task, two variables were manipulated: the memoryset size (1-6), and the target's presence or absence-a total of 12 conditions. The memory set and the memory-set size varied from trial to trial.

\section{Results and Discussion}

In both the reaction time and search/temporal-production conditions, the error rate was below $3 \%$. The mean search times are shown in Figure 1. For the positive-response trials, the slope is $33 \mathrm{msec}$; negative responses gave a slope of $39 \mathrm{msec}$. To assess the effect of memory-set size and of positive-negative response trials, a randomized block factorial design ANOVA (RBF-62) was conducted (see Kirk, 1982). As expected, the effect of memory-set size was significant $[F(5,44)=55.23, p<.01]$. The effect of positive-negative trials was also significant $[F(1,44)$ $=25.35, p<.01]$, but the interaction of memory-set size and positive-negative trials was not $(F<1)$.

Figure 2 shows the mean temporal productions. The slopes were $28 \mathrm{msec}$ for the positive-response trials, and $20 \mathrm{msec}$ for the negative-response trials. As with reaction time, temporal productions increased with memoryset size. The ANOVA (RBF-62) showed the effect of memory-set size to be significant $[F(5,30)=3.46, p<$ $.014]$. The effect of positive-negative trials $[F(1,30)=$ $1.93, p<.21]$ and the interaction of memory-set size and positive-negative trials were not significant $[F(5,30)=$ $1.21, p<.33]$.

As was previously found by Fortin and Rousseau (1987), increasing the number of comparisons in shortterm memory lengthens the temporal productions when the search is interpolated in the interval. In Fortin and

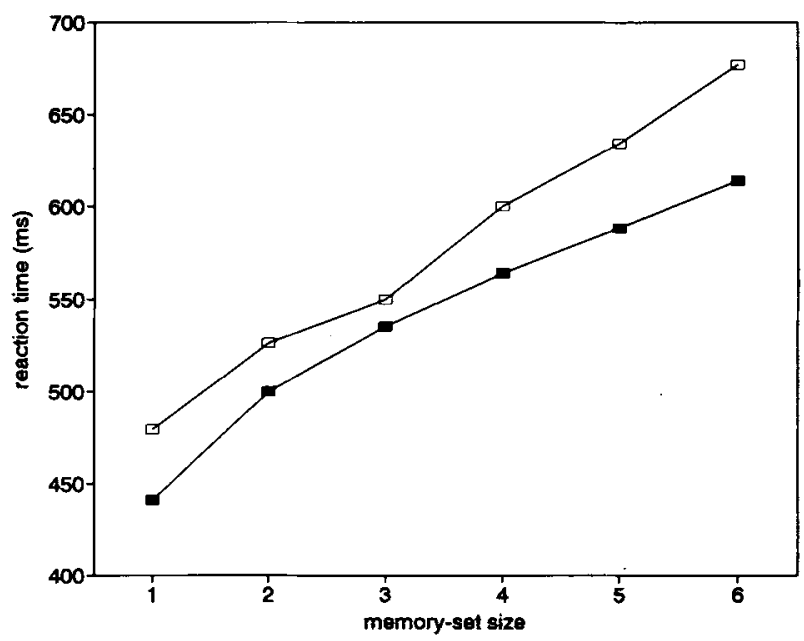

Figure 1. Mean reaction time as a function of memory-set size in Experiment 1 for positive (filled squares) and negative (open squares) trials. 


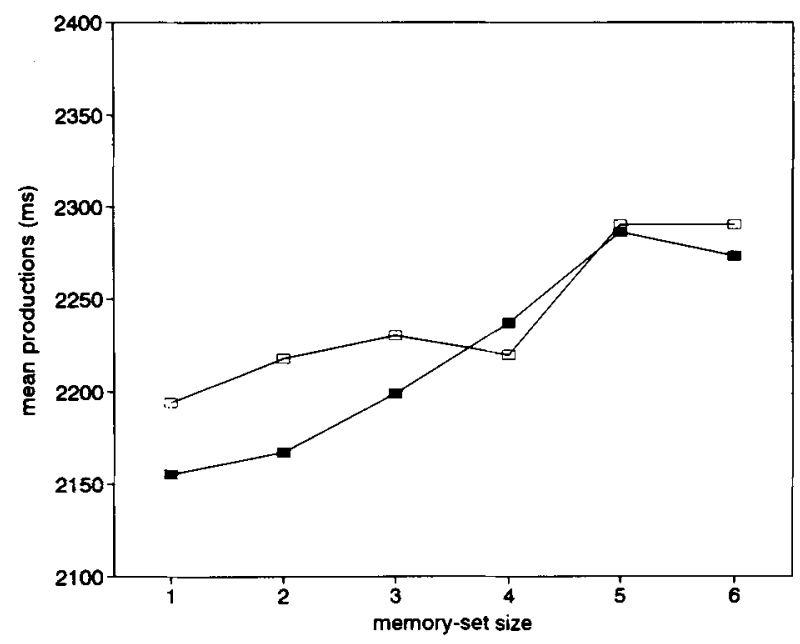

Figure 2. Mean temporal production as a function of memoryset size in Experiment 1 for positive (filled squares) and negative (open squares) trials.

Rousseau, the slopes were 21 and $24 \mathrm{msec}$ in the negative and positive trials, respectively-values quite similar to those obtained in the present experiment (28 and $20 \mathrm{msec}$ ). Increasing the number of items involved in the search seems to induce lower slope values with temporal productions than with reaction time. This is a trend that is confirmed in the present experiment; with the same experimental setting, the mean slope is $24 \mathrm{msec}$ with temporal productions, and is $36 \mathrm{msec}$ with reaction time. This suggests that some operations in search and time processing could be performed simultaneously.

\section{EXPERIMENT 2}

The results of Experiment 1 suggest that operating in short-term memory interferes with time estimation. In Experiment 2, we wanted to see if a visual search task, which requires less processing in short-term memory than the search task of Experiment 1, would interfere with temporal production. To achieve this goal, a visual search involving comparisons in short-term memory was combined with time production. The main difference with Experiment 1 is that the memory-set size was always 1 . The number of elements presented visually could vary from one to five. As noted by Schneider and Shiffrin (1977), results very similar to those obtained in Sternberg's (1966) paradigm are observed in such a situation. In the prototype of this visual search paradigm, linear-set size functions with slopes of about $25 \mathrm{msec} / \mathrm{item}$ led Atkinson, Holmgren, and Juola (1969) to conclude that a serial comparison process was carried out. However, even if these results are comparable to those obtained in a standard memory search, it can be readily argued that maintaining a single item in memory while the other items are present in the display minimizes short-term-memory involvement in the task. In particular, a memory-search task requires one to maintain a number of items in short-term memory, to compare the target to each item in memory, and to switch successively from one item to the other. The visual search task used in Experiment 2 also required mental comparison. However, memory load was reduced, and switching in short-term memory was not necessary during the comparison process, because the items were presented visually and remained present until the subject responded. Experiment 2 should shed some light on the component of the search that interferes with time estimation.

\section{Method}

Subjects. Ten young adults, ranging in age from 19 to 23 , were run in this experiment. One subject did not complete the experiment, so his results have been eliminated from the analysis.

Apparatus. In a sound-attenuating test chamber, stimulus cards were displayed in a Gerbrands four-channel tachistoscope at a viewing distance of $72 \mathrm{~cm}$. Feedback for the temporal-production task was given through headphones; feedback for the detection task was provided visually. In all other respects, the apparatus was the same as that used in Experiment 1.

Stimuli. Twenty consonants were used for both the target letters and the distractors. The array varied from one to five elements in length. Within each category, every consonant was used once at each serial position. One hundred different arrays were made, with 20 arrays per set size. No consonant could be presented more than once in a given display. The numeral character " 5 " was used as a delimiter on each side of the display. Each display was paired with a single consonant card, which contained the target to be searched in the display. At each set size, the 20 consonants were used as targets. The target was included in the display on half of the trials. The displays were composed of white cards with black Letraset numbers and uppercase letters $.6 \mathrm{~cm}$ in height. The visual angle subtended by the largest display was $2.3^{\circ}$ in width and $0.4^{\circ}$ in height.

Procedure. Each of the six experimental sessions included five blocks of trials. The experiment was divided into three parts: two sessions of visual search in a reaction time paradigm (A), two sessions of time-interval production (B), and two sessions of visual search and time-interval production in a dual-task paradigm (C).

Four subjects were tested following an AABBCC order, and the remaining 5 subjects performed the tasks in a BBCCAA order. The reaction time $(A)$ and dual-task $(C)$ sessions were composed of 50trial blocks. In the time-production sessions (B), the blocks included 40 trials.

In the first block of the reaction time session, the subject was presented with 50 practice trials that provided training with the apparatus. These trials were initiated by pressing the middle key. An arrow appeared $500 \mathrm{msec}$ later, and, depending on its direction (left or right), the subject pressed the left or right key as quickly as possible. The last four blocks were composed of 50 experimental trials, with the following sequence of events. A target letter was presented, and the subject pressed the middle key to display a fixation point. The point was displayed for $500 \mathrm{msec}$ and was immediately followed by the test display. The subject responded as quickly as possible by pressing the right or the left button if the target was present or absent in the display, respectively. No feedback was given. In these sessions, the last four blocks included a total of 200 trials in which each of the 100 arrays was used twice, once in the first two blocks and once in the last two blocks.

In the first four blocks of the time-production sessions, the subject produced 2-sec intervals. As in the first experiment, feedback was provided on temporal production. An auditory signal of high, low, or medium frequency informed the subject that the interval 
was under, over, or within a 200-msec window centered on the 2-sec standard. In the fifth block, the subject's task was to produce a 2-sec interval without feedback while performing a simple detection task, as in the last four blocks of the practice sessions in Experiment 1.

In the dual-task condition, the first block was composed of 50 trials of 2-sec temporal productions with feedback. In the experimental trials of the next four blocks, the target, which varied from trial to trial, was presented until the subject started the interval. This was immediately followed by a fixation point that stayed on for $500 \mathrm{msec}$. After the disappearance of the fixation point, the display was presented and remained present until the subject ended the interval by pressing one of two keys, depending on whether the target was or was not included in the display. The arrays used in the search component of the dual task were the same as those used in the reaction time condition.

\section{Results and Discussion}

Error rates were moderate; they averaged $5.4 \%$ in the reaction time condition and $3.1 \%$ in the dual-task condition and were not systematically related to display size. The effects of set size and of positive-negative trials on reaction time and temporal productions were tested in an ANOVA (RBF-52). The mean reaction times averaged over subjects are graphed as a function of set size in Figure 3. With reaction time data, the main effects of set size $[F(4,72)=26.72, p<.001]$ and of positive-negative trials $[F(1,72)=12.95, p<.001]$ were significant. The positive-negative trials $\times$ set size interaction was not statistically significant $[F(4,72)=1.98, p<.11]$. The slopes of mean reaction time as a function of set size were 23 and $34 \mathrm{msec}$ in the positive- and negative-response conditions, respectively.

The mean temporal intervals are shown as a function of set size in Figure 4 . The effects of set size $[F(4,72)=$ $5.60, p<.001]$ and of positive-negative trials $[F(4,72)=$ $27.10, p<.001]$ were significant. The positive-negative trials $\times$ set size interaction was also significant $[F(4,72)=4.63, p<.002]$. Simple main effects tests

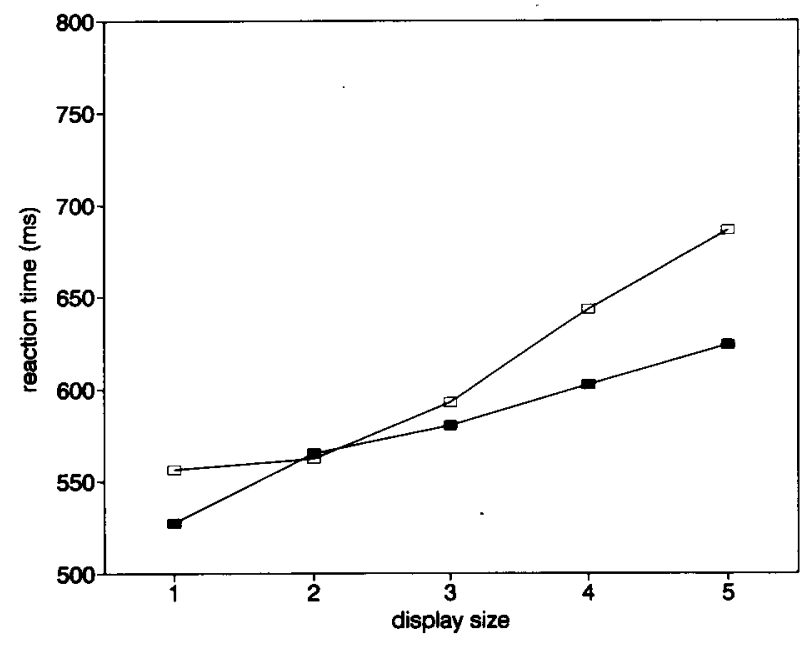

Figure 3. Mean reaction time as a function of display size in Experiment 2 for positive (filled squares) and negative (open squares) trials.

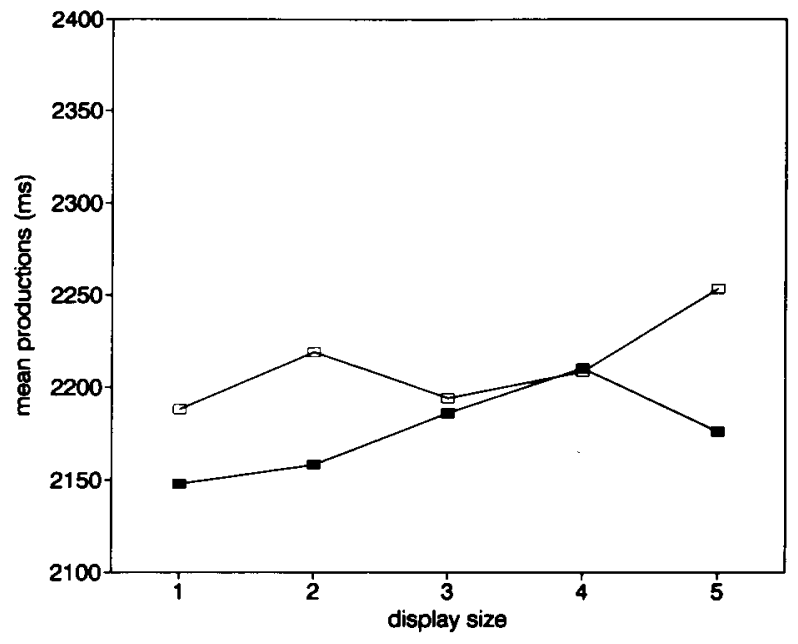

Figure 4. Mean temporal production as a function of display size in Experiment 2 for positive (filled squares) and negative (open squares) trials.

were performed to test the effect of set size on positive and negative trials. The significance of the tests was determined by using the simultaneous test procedure (see Kirk, 1982). On these tests (with a critical value of $F=$ 5.0 ), the effect of set size appeared to be significant on negative trials $[F(4,72)=5.44]$, but not on positive trials $[F(4,72)=4.78]$. Negative responses gave a slope of 12 msec per item; positive responses gave a slope of $11 \mathrm{msec}$ per item.

The purpose of this experiment was to show that a visual search task, putting less of a load on short-term memory than the memory search in Experiment 1, would produce less interference with time production. The results do not clearly support this hypothesis, because the effect of display size on the mean temporal productions is still significant in Experiment 2, at least on negative trials. Experiments 1 and 2 share two main features: the subjects were required to search items in short-term memory, and the mapping between responses and targets/distractors was varied, that is, items that were distractors in a given trial could be members of the memory set in another trial.

However, the effect of display size in Experiment 2 seems weaker than that in Experiment 1. In fact, on positive trials, the display-size effect failed to reach significance, and the mean slope of temporal productions versus display size is about half the corresponding mean slope found in Experiment 1 (11.5 msec vs. $24 \mathrm{msec})$. This could be attributed to the fact that the memory-search load varied from one experiment to the other. In Experiment 1, the memory set included from one to six items; in Experiment 2, a single item was entered into short-term memory. In a given trial, the subject had to memorize the item, and, maintaining it in memory, compare it with the display items. Regardless of the number of mental comparisons, the mean number of elements to maintain in short-term memory was lower in Experiment 2 than in Experiment 1. 
Moreover, the fact that there could be more than one item in memory in Experiment 1 involves some supplementary managing in short-term memory, for example, switching between memory-set items. In fact, Schneider and Shiffrin's (1977) data showed that a search process in short-term memory depends not only on the number of mental comparisons to be made, but also on switching from one item to another in memory. Therefore, we could conclude that the differential effect of search on time production is explained by the different demands on shortterm memory in Experiments 1 and 2.

Unfortunately, there also seems to be a general lessening of task complexity from Experiment 1 to Experiment 2 , as revealed by the weaker slopes of reaction time data in Experiment 2 than in Experiment 1 ( $28.5 \mathrm{msec}$ vs. $36 \mathrm{msec}$, respectively). It could thus be argued that in Experiment 2 , the effect of search on time production is not as strong as in Experiment 1, because of the general decrease in task complexity from Experiment 1 to Experiment 2 , and not the reduced load on short-term memory.

To clarify this issue, we need to show a clear dissociation between reaction time and temporal-production functions. If the observed lengthening of time production is attributable to processing in short-term memory, this could be achieved by using a visual search task that puts no load on short-term memory. Such a visual search task should use a single target throughout the experiment, so that a new target does not have to be entered into short-term memory on each trial. This should lead to a flat function of mean temporal production versus set size. However, in order to show the dissociation, the visual search task should clearly give significant linear increasing functions of reaction time versus display size.

Treisman and her colleagues have extensively studied spatial attention tasks, in particular, search for targets that are defined by a single or a combination of features. These experiments clearly demonstrated that searching for targets defined by a single physical feature (e.g., color or a curved shape) may be independent of the number of distractors in the visual display (Treisman \& Gelade, 1980; Treisman \& Gormican, 1988; Treisman \& Souther, 1985). These findings are contrasted with set-size-dependent search, which occurs when a target is defined by a conjunction of features, such as shape and color. In this case, for example, if subjects have to find a green $T$ among green Xs and brown Ts, detection latencies are positively related to display size, which is generally interpreted as reflecting serial search. As stated by Treisman and Souther: "When search is serial, we infer that it requires focused attention. In fact we equate attention in this context with the serial scanning device, as if a mental spotlight was directed to each item in turn in order to allow its accurate identification" (p. 287). Focused attention seems to be involved, for example, if the target is defined .by a conjunction of features (e.g., Treisman \& Gelade), or by the absence of a feature that is present in all items except the target (e.g., Treisman \& Souther). For instance, if subjects have to search for a circle without an intersecting line among circles with lines, reaction time increases linearly with the number of distractors.

Thus, spatial visual search tasks can induce large increases in reaction time as a function of display size without involving processing in short-term memory. Consequently, display size should not affect temporal productions if temporal processing specifically requires shortterm-memory resources. Furthermore, combining such search tasks with temporal production could provide a strong test of attentional models of time estimation, which hold that estimated duration is a function of the amount of attention allocated to the passage of time (Zakay, 1989). If a general attentional process is responsible for interference from search tasks, a significant effect of display size on time production should be observed.

\section{EXPERIMENT 3}

Experiment 3 was designed to test the dissociation between reaction time functions and temporal-production functions with a visual search task, in which a single feature distinguishes the target from the distractors. Two main conditions of visual search were used. In the featurepresent condition, the feature was present and the distractors lacked the same feature. In the feature-absent condition, the target did not possess this feature, but it was present in the distractors. Treisman and Souther (1985) demonstrated that these two conditions lead to a clear asymmetry between reaction time functions-the presence of the intersecting line is detected quickly and with little effect of display size, and searching for the target without the intersecting line is obviously dependent on set size. Treisman and Souther concluded that searching for the presence of the feature could be performed preattentively, and that searching for the absence of the same feature required focused attention. Thus, whereas reaction time should vary with the manipulations of feature presence and absence, time productions should be insensitive to search conditions.

\section{Method}

Subjects. Eight subjects, between the ages of 18 and 29, were run in this experiment.

Apparatus. The apparatus was as described in the General Method section.

Stimuli. The displays contained circles that could, or could not, be intersected by a vertical line $(Q$ and $O)$. The circles subtended $1.4^{\circ}$, the line, $1.0^{\circ}$. The midpoint of the vertical line intersected the circle at the lowest point of its circumference. The items were black, and appeared on a white background frame that subtended $7.2^{\circ} \times 10.7^{\circ}$. The targets and distractors were randomly scattered within the frame. In the feature-present condition, the target was the circle intersected by the line, and the distractors were the circles. In the feature-absent condition, the target was the circle, and the distractors were the circles intersected with lines. In both conditions, display sizes of 1,6 , and 12 were used, and for each display size 24 displays were made -12 with the target and 12 without. A total of 72 displays was constituted in both the feature-present and feature-absent conditions, for a total of 144 displays used in the experiment. 
Procedure. Four subjects performed the visual search task in a reaction time condition, 4 in a visual search and time-intervalproduction dual-task condition. Each group of 4 subjects was divided into two groups of 2 subjects, which were run in the feature-present and feature-absent conditions in a counterbalanced order.

There were four experimental sessions in the reaction time condition: two in the feature-present condition and two in the featureabsent condition. In these sessions, the subjects completed four blocks of 72 trials with a $10-\mathrm{sec}$ rest after each block. There were 36 displays with the target, and 36 without the target in each block. In both conditions, with and without the target, 12 displays were presented for each display size of 1,6 , or 12 elements. Within each block, the presentation order of the trials with and without targets and of the different display sizes was randomized. Between trials, a central fixation dot was presented. When ready, the subject pressed the middle key, which initiated a 500-msec delay. The fixation dot remained present during this delay, then the display appeared. The display remained present until the subject responded by pressing, as quickly as possible, the left key if the target was absent, and the right key if the target was present, while minimizing errors. Immediately after the response, visual feedback was presented for $500 \mathrm{msec}$, informing the subject if it was a with- or a without-target trial.

There were seven sessions in the visual search/time-intervalproduction condition: three temporal-production practice sessions and four search and time-production dual-task sessions - two in the feature-present condition and two in the feature-absent condition.

The temporal-production practice sessions included four blocks of 72 trials, in which the subject had to produce a 3-sec temporal interval. The time intervals were produced by first pressing the starting key (the digit 0 on the numerical keyboard). After a subjective 3-sec interval, the subject ended the temporal production by pressing one or the other of the two keys located above the starting key, depending on the direction (left or right) of an arrow that was presented on the screen during the interval. In the first three blocks, auditory feedback informed the subject if the time interval produced was over, under, or within a 300-msec window centered on the 3-sec standard. In the fourth block, no feedback was provided.

After the three temporal-production practice sessions, the search and time-production dual-task sessions were introduced. These were composed of a first block of $\mathbf{2 0}$ temporal-production practice trials to reset the productions around the target duration, followed by four blocks of 72 trials of the search and time-production dual task. In these trials, a fixation point appeared. The subject started the interval by pressing the starting key, as in the practice sessions. The fixation point disappeared $500 \mathrm{msec}$ after this first buttonpress, and this was followed immediately by the visual display. After the subjective 3-sec interval, the subject ended the interval by pressing one of the two keys (left or right) above the starting key, depending on the absence or presence of the target. Visual feedback followed the end of the interval, informing the subject if the target was present or absent in the display. No feedback' on the time-production performance was provided in these experimental trials.

\section{Results and Discussion}

The mean reaction times as a function of display size are shown in Figures 5 and 6. Error rates were low: 2.0\% in the feature-present condition, and $2.5 \%$ in the featureabsent condition. In the feature-absent condition, an ANOVA (RBF-32) revealed significant effects of display size $[F(2,15)=383.13, p<.001]$ and of positivenegative trials $[F(1,15)=196.08, p<.001]$ on reaction time. The interaction between display size and positive-negative trials was significant $[F(2,15)=19.52$, $p<.001]$. In the feature-absent condition, the slopes

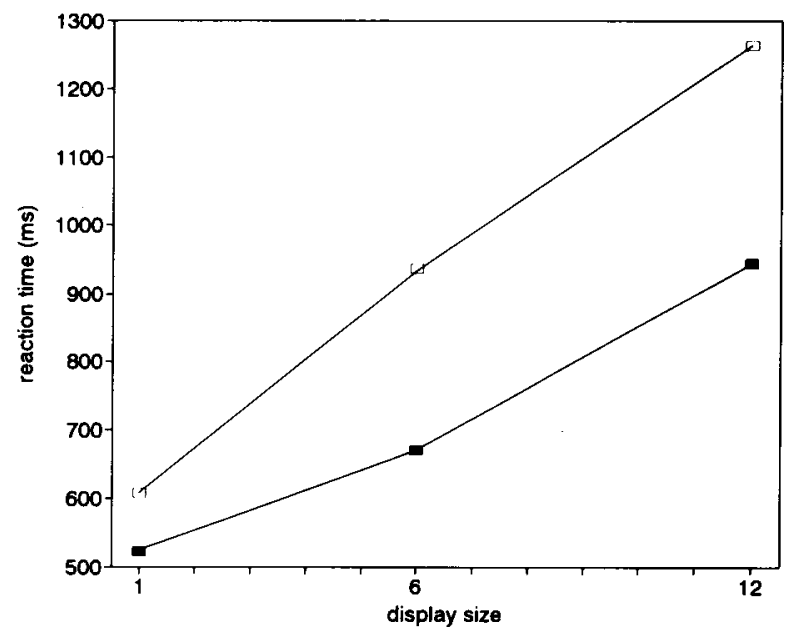

Figure 5. Mean reaction time as a function of display size in the feature-absent condition of Experiment 3 for positive (filled squares) and negative (open squares) trials.

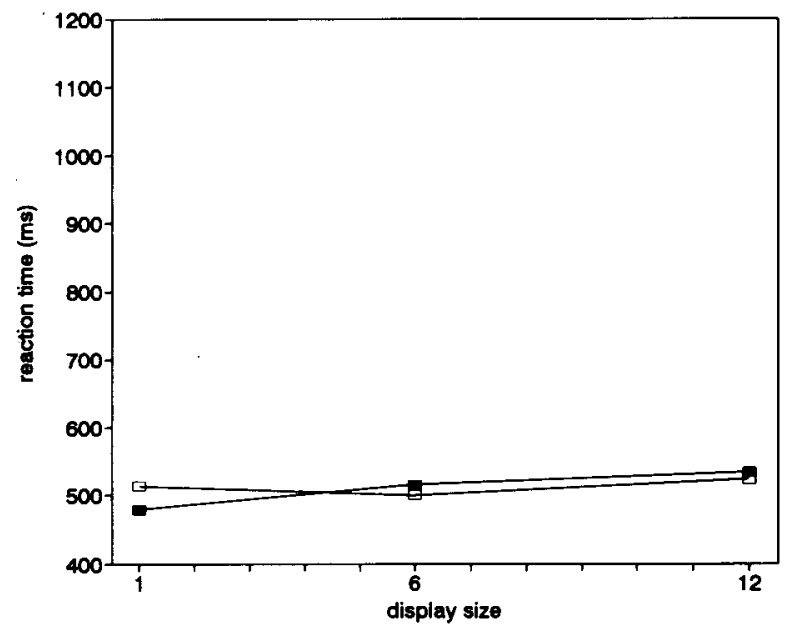

Figure 6. Mean reaction time as a function of display size in the feature-present condition of Experiment 3 for pasitive (filled squares) and negative (open squares) trials.

were $39 \mathrm{msec}$ when the target was present, and $59 \mathrm{msec}$ when the target was absent. In the feature-present condition, the effects of display size $[F(2,15)=4.08, p<$ $.03]$, of positive- negative trials $[F(1,15)=1.13, p<$ $.31]$, and the interaction between display size and target were not significant $(F<1)$.

Figures 7 and 8 show the mean temporal intervals as a function of display size in the feature-absent and featurepresent conditions. Error rates were negligible: $0.6 \%$ in the feature-present condition, and $0.4 \%$ in the featureabsent condition. As with the reaction time data, ANOVAs (RBF-32) were run in both conditions. In the featureabsent condition, the main effect of display size did not reach significance $[F(2,15)=5.36, p<.02]$, and the 


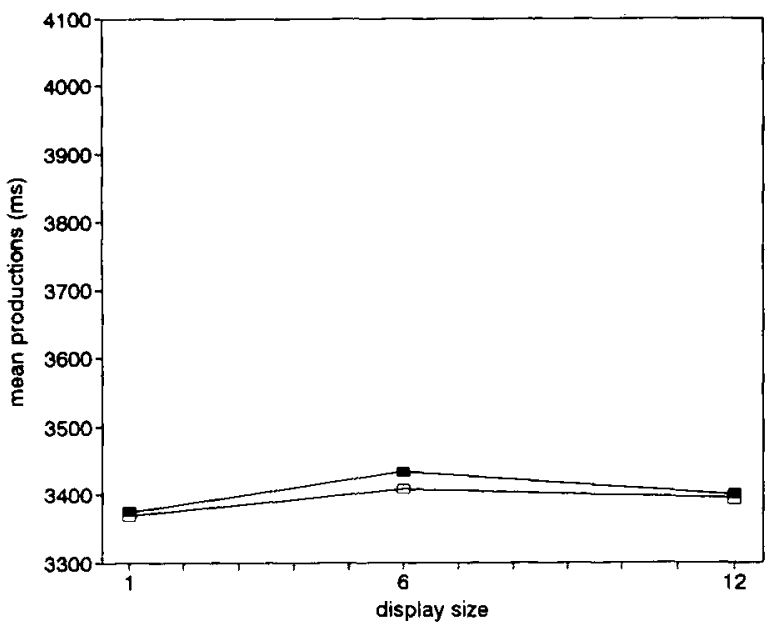

Figure 7. Mean temporal production as a function of display size in the feature-absent condition of Experiment 3 for positive (filled squares) and negative (open squares) trials.

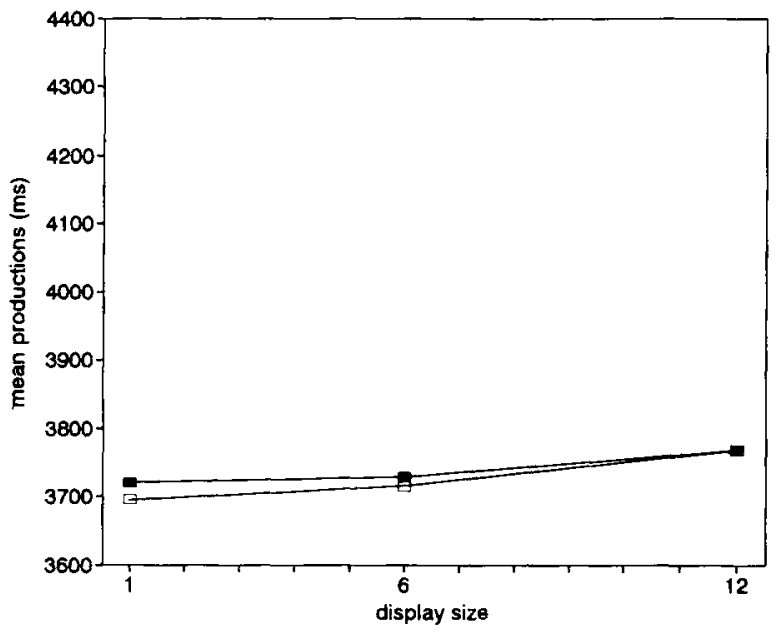

Figure 8. Mean temporal production as a function of display size in the feature-present condition of Experiment 3 for positive (filled squares) and negative (open squares) trials.

effect of positive-negative response and the interaction between display size and positive-negative response were also not significant $(F s<1)$. When the feature was present in the target, there was no significant effect of display size $[F(2,15)=4.08, p<.04]$, of positivenegative response $[F(1,15)=1.13, p<.31]$, or of the interaction between display size and positive-negative trials $(F<1)$.

The most important finding in Experiment 3 is the clear dissociation between reaction time and temporalproduction functions in the feature-absent condition. Reaction time data replicate well those of Treisman and Souther (1985). Similar (and even weaker) slopes led Treisman and Souther to conclude that in the feature-absent condi- tion, the target is detected through a slow and apparently serial search, requiring about $40 \mathrm{msec}$ to check each distractor, thus requiring attention to be focused serially on each in turn. The results of Experiment 3 demonstrate that it is possible to perform this attention-demanding task without any interference from a simultaneous timeproduction task.

This clearly contradicts statements such as "[if] less attention can be devoted to the cognitive counter ... fewer subjective time units [are] accumulated in it" (Zakay, 1989 , p. 368). This view, widely held in the literature on attentional models of time estimation, would predict a lengthening of temporal productions with display size in the feature-absent condition of Experiment 3. That was not what was actually observed. Furthermore, and most important, Experiments 1 and 2 showed that this pattern could be observed by using a short-term-memory scanning task. These results provide impressive support to our hypothesis that the interference, in Experiments 1 and 2, is not attributable to an attentional load itself, but rather to the short-term-memory component of the nontemporal task.

\section{EXPERIMENT 4}

In Experiment 4, we investigated whether the results of Experiment 3 depended on the specific stimuli used, which were not digits or letters as in Experiments 1 and 2. In Experiment 4, the displays were composed of letters, as in Experiment 2. A visual search task was again interpolated in temporal productions. The effect of searching for targets that were defined by a conjunction of features, or by disjunctive features, was studied in the reaction time and time-production conditions.

\section{Method}

Subjects. Eight subjects, between the ages of 21 and 31, served as paid subjects.

Apparatus. The apparatus was the same as that used in Experiment 3.

Stimuli. The displays used in the experimental sessions contained stimuli subtending $0.4^{\circ} \times 0.2^{\circ}$. The distractors were brown Ts and green Xs on a white background, of approximately equal numbers. In the conjunction condition, the target was a green $T$, and in the feature condition, the target could be a blue letter ( $\mathrm{T}$ or $\mathrm{X}$ ) or an S, which could be brown or green. Targets and distractors were scattered haphazardly over the display, which subtended $7.2^{\circ} \times 10.7^{\circ}$. Three display sizes of 1,5 , and 15 items were used. For each display size and each condition (feature and conjunction), 24 displays -12 with target, 12 without target-were prepared.

Procedure. Each group of 4 subjects was divided into two groups, which were run in the feature and conjunction conditions in a counterbalanced order.

In the reaction time condition, the procedure was the same as in Experiment 3, except there were five blocks in the four experimental sessions. The task was to search for the conjunction target (green T) in the conjunction condition, and the feature target (blue letter, or $S$ ) in the feature condition.

In the visual search/time-interval-production condition, the procedure was the same as that used in Experiment 3. A visual search, as just described, was interpolated in the temporal production. 


\section{Results and Discussion}

The mean reaction times for each display size are shown in Figures 9 and 10 for the conjunction and the feature conditions, respectively. The error rates averaged $2.6 \%$ in the conjunction condition, and $2.1 \%$ in the feature condition. ANOVAs were carried out on the reaction time data for the feature and conjunction conditions, to assess the effect of display size and of positive-negative response trials (RBF-32). In the conjunction condition, the analysis showed a significant effect of display size $[F(2,15)=$ $15.16, p<.001]$ and of positive-negative trials $[F(1,15)$ $=11.24, p<.004$ ], but the interaction between size and positive-negative trials was not significant $[F(2,15)=$ $4.07, p<.04$ ]. In the feature condition, the main effect

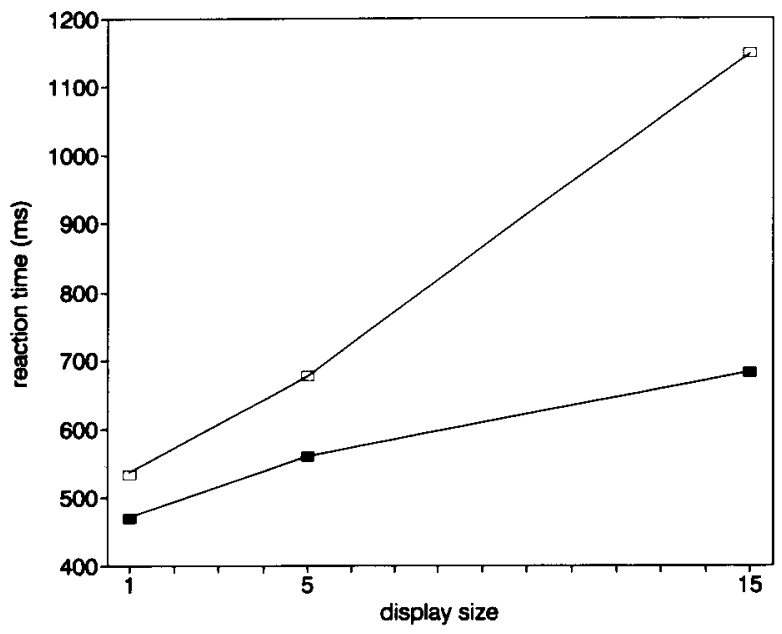

Figure 9. Mean reaction time as a function of display size in the conjunction condition of Experiment 4 for positive (filled squares) and negative (open squares) trials.

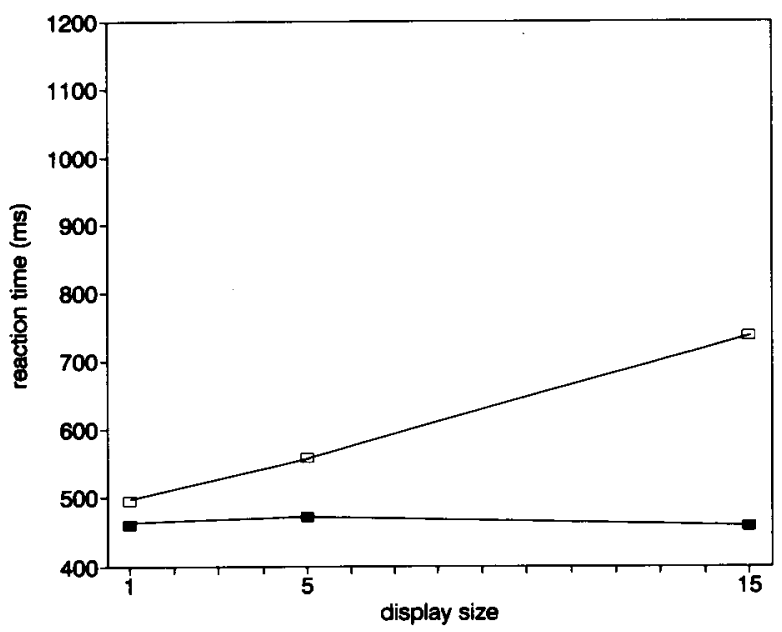

Figure 10. Mean reaction time as a function of display size in the feature condition of Experiment $\mathbf{4}$ for positive (filled squares) and negative (open squares) trials. of display size reached significance $[F(2,15)=5.97, p<$ $.012]$, as did the effect of positive-negative trials $[F(1,15)$ $=21.42, p<.001]$. The interaction between display size and positive-negative trials was also significant $[F(2,15)=$ $6.60, p<.009]$. The slopes of mean reaction times were, in the conjunction condition, $15 \mathrm{msec}$ for the positive trials, and $45 \mathrm{msec}$ for the negative trials. In the feature condition, the slopes for the positive and negative trials were $-0.4 \mathrm{msec}$ and $17 \mathrm{msec}$, respectively.

Figures 11 and 12 show the mean temporal productions averaged over the 4 subjects as a function of display size in the conjunction and feature conditions: The mean error rates were $1.3 \%$ in the conjunction condition, and $1.0 \%$ in the feature condition. In the conjunction condition, there was a significant decrease of time production as a function of display size $[F(2,15)=10.34, p<.002]$. There was no effect of positive-negative trials, nor of an interaction between display size and positive-negative trials $\left(F_{\mathrm{S}}<1\right)$. In the feature condition, there was no effect of display size $[F(2,15)=3.88, p<.04]$, of positivenegative trials $[F(2,15)=1.53, p<.25]$, nor of the interaction between display size and positive-negative trials $(F<1)$. The slopes of mean productions were, in the conjunction condition, $-5 \mathrm{msec}$ and $-4 \mathrm{msec}$ for the positive and negative trials, respectively. In the feature condition, the corresponding slopes were $-5 \mathrm{msec}$ and -6 msec.

In this experiment, as in Experiment 3, there is no lengthening of temporal intervals with display size, although there is a clear effect of display size on reaction time. For example, even if the slope of mean reaction time in the negative conjunctive search is $45 \mathrm{msec}$, the corresponding slope, in the search/time-production condition is $-4 \mathrm{msec}$. In Experiment 1 , the mean slope of reaction time versus memory-set size is $33 \mathrm{msec}$; the corresponding slope, in search/time production is $28 \mathrm{msec}$. It is thus possible to conclude that operating the serial scanning device that Treisman and Souther (1985) equate with attention does not interfere with time estimation in the same way that the serial scanning device that operates in short-term memory does.

However, a slight decrease of the mean intervals with increasing the display size appeared to be significant in Experiment 4. Although this trend was statistically significant only in the conjunction condition, it was also observed in the feature condition; the slopes were also negative in this condition and of similar values, about $-5 \mathrm{msec}$. It is difficult to come to a conclusion about this trend because it reached statistical significance in the conjunction condition only, and because such a negative relation between time production and set size was observed for the first time in this experiment.

A reduction in temporal production as display size increases would correspond to an increase in perceived duration as a function of display size. Although any definite conclusion would appear somewhat speculative at this point, it must be noted that this effect could be related 


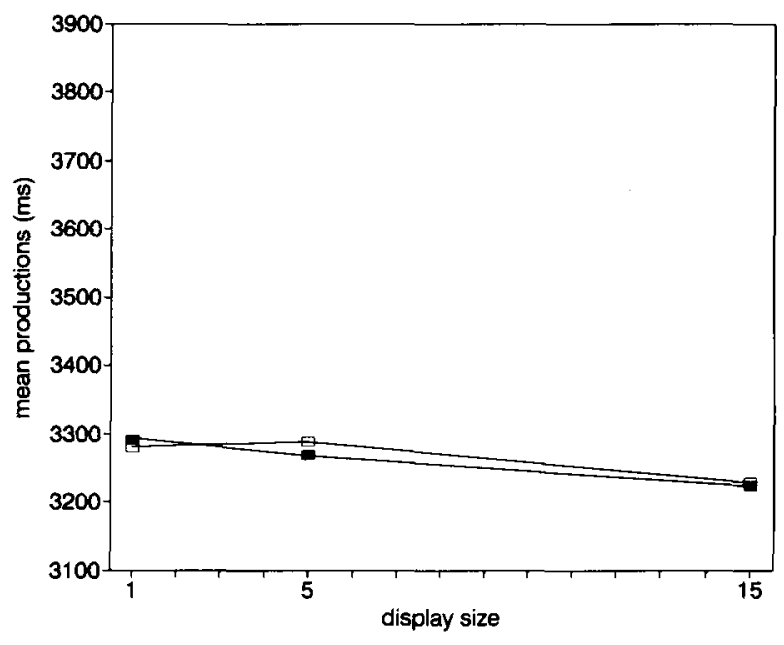

Figure 11. Mean temporal production as a function of display size in the conjunction condition of Experiment 4 for positive (filled squares) and negative (open squares) trials.

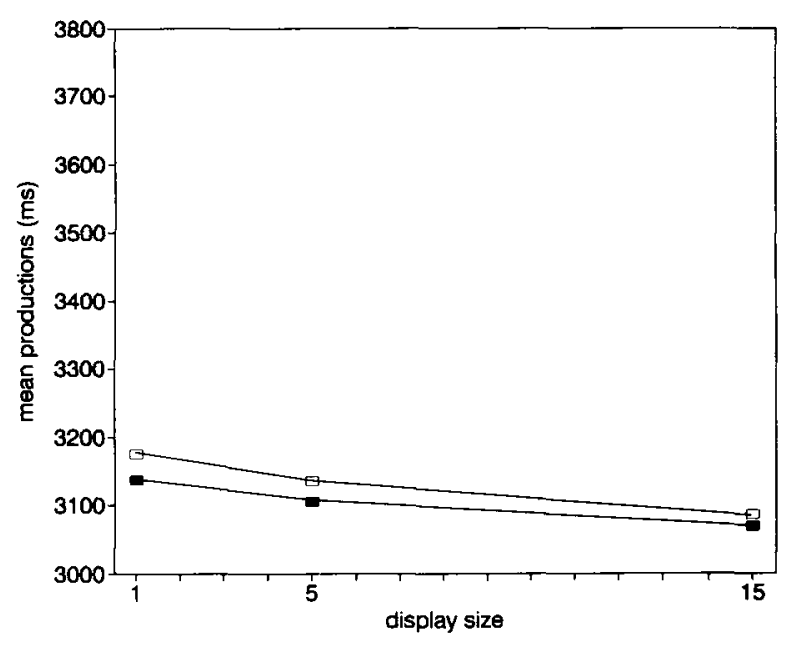

Figure 12. Mean temporal production as a function of display size in the feature condition of Experiment $\mathbf{4}$ for positive (filled squares) and negative (open squares) trials.

to a well-known phenomenon in the time perception literature called the filled-duration illusion (e.g., Goldstone \& Goldfarb, 1963; Thomas \& Brown, 1974). However, further research would be needed to confirm this trend and to explain why it appeared in these particular conditions.

\section{GENERAL DISCUSSION}

The purpose of the present study was to demonstrate that interference from search tasks on temporal production was specifically dependent on sharing short-termmemory resources. In order to do so, we sought a dissociation between reaction time slopes as a function of number of items and temporal production slopes. We in- tended to use such a dissociation to discriminate between the usual interpretation of nontemporal processing interference on time judgments in terms of task difficulty or complexity and interference specific to processing in short-term memory.

quired to accomplish a task, and task difficulty refers to the speed or accuracy of performance (Kantowitz, 1985; Kantowitz \& Knight, 1976; Navon, 1984). In the preceding experiments, task complexity was varied within experiments by set-size manipulations. Varying search-task complexity did not produce the same effect on temporal production across experiments. This cannot be explained by arguing that the tasks were of varying levels of difficulty, because the speed with which the search tasks could be performed was comparable in all four experiments, as revealed by reaction time slopes. Table 1 contrasts the slopes (averaged over positive and negative trials) of reaction time and time productions as a function of set size in Experiments 1 and 2 and in the load-dependent conditions of Experiments 3 and 4. Defining task difficulty as the number of stimuli handled per unit of time, or response rate (Kantowitz \& Knight, 1976), the search tasks appear to be of comparable levels of difficulty; in all the experiments, processing could be performed at an average rate of about $40 \mathrm{msec}$ per item. Table 1 shows clearly that the difficulty of a nontemporal task performed simultaneously with a time-production task is not related to the amount of interference with time estimation.

This contradicts the conclusions from many experiments on time estimation. For instance, Zakay, Nitzan, and Glickson (1983) varied the difficulty of a verbal task and found that time estimation of this task was a decreasing function of task difficulty. McClain (1983) asked subjects to estimate the duration of a time period filled with words presented at different rates. Task difficulty was varied through the level-of-processing requirements of the words. Depending on the condition, the words had to be processed at a graphemic or a semantic level. In the semantic encoding condition, time judgments were a decreasing function of the number of stimuli to process, and the relation was inversed when graphemic processing was required. The results of these experiments were taken as evidence supporting attentional models of time estimation in which time estimation results from the accumulation of subjective temporal units corresponding to an average mental content

Table 1

Mean Slopes (Averaged Over Positive and Negative Trials) of Reaction Time and Time Productions as a Function of Set Size in Experiments 1 and 2, and in the Load-Dependent Conditions of Experiments 3 and 4

\begin{tabular}{ccc}
\multicolumn{3}{c}{ Load-Dependent Conditions of Experiments 3 and 4 } \\
Experiment & $\begin{array}{c}\text { Reaction Time } \\
\text { Slope }\end{array}$ & $\begin{array}{c}\text { Time Production } \\
\text { Slope }\end{array}$ \\
\hline 1 & 36 & 24 \\
2 & 29 & 12 \\
$3^{*}$ & 49 & 6 \\
$4 \dagger$ & 30 & -5 \\
\hline
\end{tabular}

*Feature absent. †Conjunction. 
per unit of duration (Frankenhauser, 1959; Hicks et al., 1976). If, during the accumulation, attention is diverted from the time estimation process, such as in McClain's semantic processing condition, less temporal units are collected, thus resulting in a relative underestimation.

In the present study, the results of Experiments 1 and 2 were in line with those of Zakay et al. (1983) and McClain (1983). However, in Experiments 3 and 4, the pattern of results was quite different, even though the level of difficulty of the nontemporal tasks appeared to be about the same as in Experiments 1 and 2. As noted by Zakay et al. (1983), a problem with time estimation research is that a direct comparison of results with different methods of time estimation or different objective durations is quite difficult. The four experiments of the present study used a prospective paradigm of time estimation with a production method for durations of about $3 \mathrm{sec}$. The stimuli used in the search tasks were similar from one experiment to the other, and the set sizes were of comparable values.

The main conclusion that can be drawn from the present study is that time estimation is not related to simultaneous nontemporal task difficulty per se. Even in similar experimental conditions, an interference analysis between nontemporal and temporal processing should take into account precisely which processes are involved in nontemporal processing. In the present study, we attempted to vary the load on short-term memory in four experiments. In Experiment 1, the memory-set size varied from 1 to 6. In this first experiment, a clear interference between nontemporal and temporal processing was observed, and the amount of interference was proportional to task complexity. The interference was additive, that is, the time intervals lengthened with the number of items to be processed in the search task. In Experiment 2, a single item was put into short-term memory; this target varied from trial to trial. In these conditions, the search still interfered with time production, although to a different extent: the slopes of time productions as a function of set size were weaker than in Experiment 1. In the last two experiments, a single item that was always the same throughout the experiment was used. No lengthening of time intervals as a function of task complexity was observed.

Three points in the results suggest that concurrent processing in short-term memory is the source of interference with temporal processing. First, the fact that temporal-interval data parallel those obtained with reaction time when short-term-memory search is interpolated, as in Experiment 1, signals that operating in short-term memory seems to interfere specifically with time estimation. Second, there seems to be a lessening of the effect of set size on temporal intervals with a concurrent search task, which puts less of a load on short-term memory, as in Experiment 2. Finally, Experiments 3 and 4 demonstrated that time production could be unaffected by a concurrent task that requires one to actively process information, if this concurrent task does not involve processing in short-term memory.
These results, together with those of Fortin and Rousseau (1987), offer converging evidence that processing in short-term memory interferes selectively with time estimation. A structural analysis of this dual-processing situation leads to the conclusion that, in a prospective paradigm, production of brief temporal intervals would require controlled processing in short-term memory. These experimental data bring some support to Zakay's (1990) statement that prospective time estimation of short intervals relies mostly on short-term-memory processes, and also support a model of time estimation that assumes that temporal information must be stored in a short-term store before being compared with a criterion duration in a long-term store (Gibbon et al., 1984). Interestingly, some clinical data also relate short-term-memory processes and time-interval production. In the well-known clinical case of Scoville and Milner (1957), M.H. was asked to reproduce time intervals ranging from 1 to $300 \mathrm{sec}$ (Richards, 1973). Two power functions are needed to describe H.M.'s performance. For time intervals less than $20 \mathrm{sec}$, the exponent is 1.05; reproduced time approximately equals true time, as it does for normal subjects. However, for intervals longer than $20 \mathrm{sec}$, the exponent of the power function is 0.44 , an abnormally low value that reflects a crude underestimation of intervals longer than $20 \mathrm{sec}$. For intervals less than $20 \mathrm{sec}$, H.M.'s timing mechanism and his decay of short-term memory appeared normal (Wickelgren, 1968). According to the author of the experiment, his abnormal behavior in time reproductions for intervals greater than $20 \mathrm{sec}$ could be attributed to a failure in a separate longer term temporal integrator, or an inability to accurately count outputs from a shorter term integrator.

Concurrent processing in short-term memory is shown to systematically lengthen temporal production. This finding is consistent with those of numerous studies (Brown, 1985; Hicks, Miller, Gaes, \& Bierman, 1977; Hicks et al., 1976; McClain, 1983; Vroon, 1970) and with some temporal-processing models described earlier (Church, 1984; Rousseau et al., 1984), suggesting that the attentional gate enabling temporal information accumulation, or the accumulation process itself, is under short-termmemory control.

The present study is relevant to the issue of the criteria used in the selection of concurrent nontemporal tasks. The results of Experiments 3 and 4 show that an increase in reaction time is no more adequate a criterion than is the amount of stimulus information presented to the subject during temporal processing. A performance criterion that does not take into account the specific processing resources shared between temporal and nontemporal processing cannot provide a fruitful interpretation framework for an analysis of interference effects in this concurrent processing situation. This underlines a basic strength of the methodology used in the present study: it allows a microanalysis that would not have been possible with the complex nontemporal tasks often used in research on time estimation. 


\section{REFERENCES}

Atkinson, R. C., Holmgren, J. E., \& Juola, J. F. (1969). Processing time as influenced by the number of elements in a visual display. Perception \& Psychophysics, 6, 321-326.

BLOCK, R. A. (1990). Models of psychological time. In R. A. Block (Ed.), Cognitive models of psychological time (pp. 1-35). Hillsdale, NJ: Erlbaum

Brown, S. W. (1985). Time perception and attention: The effects of prospective versus retrospective paradigms and task demands on perceived duration. Perception \& Psychophysics, 38, 115-124.

Brown, S. W, WEst, A. N. (1990). Multiple timing and the allocation of attention. Acta Psychologica, 75, 103-121.

Church, R. M. (1984). Properties of the internal clock. In J. Gibbon \& L. Allan (Eds.), Timing and time perception (Annals of the New York Academy of Sciences, Vol. 423, pp. 566-582). New York: New York Academy of Sciences.

Fortin, C., RousSeau, R. (1987). Time estimation as an index of processing demand in memory search. Perception \& Psychophysics, 42, 377-382.

Fraisse, P. (1984). Perception and estimation of time. Annual Review of Psychology, 35, 1-36.

FrankENhauSER, M. (1959). Estimation of time. Stockholm: Almquist \& Wiksell.

Grbaon, J., Church, R. M., \& Meck, W. H. (1984). Scalar timing in memory. In J. Gibbon \& L. Allan (Eds.), Timing and time perception (Annals of the New York Academy of Sciences, Vol. 423, pp. 52-77). New York: New York Academy of Sciences.

Goldstone, S., GoldFare, J. L. (1963). Judgment of filled and unfilled durations: Intersensory factors. Perceptual \& Motor Skills, 17, 763-774.

GopHer, D., Donchin, E. (1986). Workload: An examination of the concept. In K. R. Boff, L. Kaufman, \& J. P. Thomas (Eds.), Hand book of perception and human performance (Vol. 41, pp. 1-49). New York: Wiley.

Hicks, R. E., Miller, G. W., Gaes, G., Bierman, K. (1977). Concurrent processing demands and the experience of time-in-passing. American Journal of Psychology, 90, 431-446.

Hicks, R. E., Miller, G. W., Kinsbourne, M. (1976). Prospective and retrospective judgments of time as a function of amount of information processed. American Joumal of Psychology, 89, 719-730.

Kahneman, D. (1973). Attention and effort. Englewood Cliffs, NJ: Prentice-Hall.

KANTowitZ, B. H. (1985). Channels and stages in human information processing: A limited analysis of theory and methodology. Joumal of Mathematical Psychology, 29, 135-174.

KanTowitz, B. H., KNIGHT, J. L. (1976). Testing tapping timesharing: II. Auditory secondary tasks. Acta Psychologica, 40, 342-362.

KILleEn, P. R., Weiss, N. A. (1987). Optimal timing and the Weber function. Psychological Review, 94, 455-468.

KIRK, R. E. (1982). Experimental design: Procedures for the behavioral sciences (2nd ed.). Belmont, CA: Brooks/Cole.

Kristofferson, A. B. (1977). A real-time criterion theory of duration discrimination. Perception \& Psychophysics, 21, 105-117.

MCCLAIN, L. (1983). Interval estimation: Effect of processing demands on prospective and retrospective reports. Perception \& Psychophysics, 34, $185-189$.

MECK, W. H. (1984). Attentional bias between modalities: Effect on the internal clock, memory, and decision stages used in animal time discrimination. In J. Gibbon \& L. Allan (Eds.), Timing and time perception (Annals of the New York Academy of Sciences, Vol. 423, pp. 528-541). New York: New York Academy of Sciences.

Navon, D. (1984). Resources: A theoretical soup stone? Psychological Review, 91, 216-234.

Navon, D., GopHER, D. (1979). On the economy of the human processing system. Psychological Review, 86, 214-255.
Norman, D. A., \& Bobrow, D. G. (1975). On data-limited and resource-limited processes. Cognitive Psychology, 7, 44-64.

RABBITT, P. (1984). The control of attention in visual search. In R. Parasuraman \& D. T. Davies (Eds.), Varieties of attention (pp. 273-291). New York: Academic Press.

Richards, W. (1973). Time reproductions by H.M. Acta Psychologica, 37, 279-282.

Rousseau, R., Fortin, C., \& Kirouac, E. (in press). Sensibilité et diagnosticité de la mesure de la charge mentale par la tâche secondaire de frappe cadencée. Revue Canadienne de Psychologie/Canadian Joumal of Psychology.

Rousseau, R., Picard, D., \& Pitre, E. (1984). An adaptive counter model for time estimation. In J. Gibbon \& L. Allan (Eds.), Timing and time perception (Annals of the New York Academy of Sciences, Vol. 423, pp. 639-642). New York: New York Academy of Sciences. Schneider, W., \& Shiffrun, R. M. (1977). Controlled and automatic human information processing: I. Detection, search, and attention. Psychological Review, 84, 1-66.

SCHWEICKERT, R., BoGGs, G. J. (1984). Models of central capacity and concurrency. Joumal of Mathematical Psychology, 28, 223-281.

SCOVILLE, W. B., \& MiLNeR, B. (1957). Loss of recent memory after bilateral hippocampal lesions. Journal of Neurology, Neurosurgery, \& Psychiatry, 20, 11-21.

SternberG, S. (1966). High-speed scanning in human memory. Science, 153, 652-654.

Thomas, E. A. C., Brown, I., JR. (1974). Time perception and the filled-duration illusion. Perception \& Psychophysics, 16, 449-458.

Thomas, E. A. C., \& CANTOR, N. E. (1978). Interdependence between the processing of temporal and non-temporal information. In J. Requin (Ed.), Attention and performance VII (pp. 43-62). Hillsdale, NJ: Erlbaum.

Treisman, A., \& Gelade, G. (1980). A feature integration theory of attention. Cognitive Psychology, 12, 97-136.

Treisman, A., Gormican, S. (1988). Feature analysis in early vision: Evidence from search asymmetries. Psychological Review, 95, $15-48$.

Treisman, A., Souther, J. (1985). Search asymmetry: A diagnostic for preattentive processing of separable features. Journal of $E x$ perimental Psychology: General, 114, 285-310.

VROON, P. A. (1970). Effects of presented and processed information on duration experience. Acta Psychologica, 34, 115-121.

WiCKELGREN, W. A. (1968). Sparing of short-term memory in an amnesic patient: Implications for strength theory of memory. Neuropsychologia, 6, 235-244.

WICKENS, C. D. (1980). The structure of processing resources. In R. Nickerson \& R. Pew (Eds.), Attention and Performance VIII (pp. 239-257). Hillsdale, NJ: Erlbaum.

WiCKENS, C. D. (1984). Processing resources in attention. In R. Parasuraman \& D. T. Davies (Eds.), Varieties of attention (pp. 63102). New York: Academic Press.

ZAKAY, D. (1989). Subjective time and attentional resource allocation: An integrated model of time estimation. In I. Levin \& D. Zakay (Eds.), Time and human cognition: A life-span perspective (pp. 365397). Amsterdam: Elsevier.

ZAKAY, D. (1990). The evasive art of subjective time measurement: Some methodological dilemmas. In R. A. Block (Ed.), Cognitive models of psychological time (pp. 59-84). Hillsdale, NJ: Erlbaum.

ZakaY, D., Nitzan, D., Guckson, J. (1983). The influence of task difficulty and external tempo on subjective time estimation. Perception \& Psychophysics, 34, 451-456.

(Manuscript received June 26, 1992; revision accepted for publication October $12,1992$. 